\title{
Adsorption of cationic dye onto fly ash-based geopolymer: Batch and fixed bed column studies
}

\author{
Marouane El Alouani, Saliha Alehyen, Mohammed El Achouri and M'hamed Taibi \\ Mohammed V University in Rabat, Centre des Sciences des Matériaux (CSM), (LPCMIO), Ecole Normale \\ Supérieure Rabat, Morocco
}

\begin{abstract}
Cationic dye adsorption from aqueous solution onto synthesized geopolymer was investigated by batch and fixed bed column experiments. The geopolymer material was elaborated by alkali solution and fly ash supplied by Jorf Lasfar power plant of Morocco. Physical and chemical characteristics of samples were determined by FX, DRX, SEM, ${ }^{29}$ Si MAS NMR and Zeta potential methods. The Brunauer, Emmett and Teller (BET) technique is used to determine the surface area. The Barrett-Joyner-Halenda (BJH) method was performed to obtain pore size distribution curves and average pore diameter. Kinetics data were analyzed using pseudo-first-order, pseudo-second-order and intraparticle diffusion models. To predict the breakthrough curves and determine the main fixed bed column parameters, three kinetic models; Tomas, Bohart-Adams and YoonNelson models are applied to fitting the experimental data. The kinetic study showed that the pseudo-secondorder can be used to describe the methylene blue (MB) adsorption process on the geopolymer matrix. The kinetic models of the adsorption in dynamic column are suitable to describe the continuous adsorption process of dyestuff by the geopolymer. The results of this study indicated that geopolymer derived from fly ash can be used as a low cost effective adsorbent for cationic dye removal from industrial aqueous effluent.
\end{abstract}

\section{Introduction}

Synthetic organic dyes are used in many industrial sectors such as paper, leather plastic manufacture, automotive industry and textile industry. This various industrial activities are an important source of environmental pollution due to their high content of many chemical dyes.

Among the textile dyes most used in industry, methylene blue (MB) or basic blue 9. It is a watersoluble cationic dye and can reveal very harmful effects on living things such as difficulties in breathing, vomiting, diarrhea, nausea and several negative impacts on the aquatic environment [1]. Therefore it is very important to confirm the water quality, since even just 1.0 $\mathrm{mg} / \mathrm{L}$ of dye concentration in drinking water can impart a significant color, making it unfit for human consumption [2]. Therefore, it is necessary to reduce dyes concentration in aqueous media and wastewater.

Recently, many different technologies have been utilized for removal of hazardous pollutants from water and wastewater, including biochemical methods [3], membrane separation [4], ion-echange [5], ultrafiltration [6], photocatalysis [7], coagulation/flocculation [8], and adsorption [9]. Among the mentioned methods, adsorption has some advantage when compared aforementioned conventional methods in terms the simplicity of utilization, effectiveness, low cost, no sludge formation, etc. However, natural and synthetic materials with low cost treatment such a bentonite, kaolinite, silicate, natural phosphate, activated carbon and fly ash based geopolymer have been applied for removal the organic pollutants from water contaminated by pollutants [10-13]. In recent years, many authors are interested in the synthesis of the adsorbents powdered and granulated goepolymer for removing the organic pollutants from aqueous media and wastewaters by the adsorption method [14-16]. The batch and column adsorption of organic pollutants from aqueous solutions by goepolymer has been studied by various scientists [1719].

In this work, the geopolymer developed by fly ash and alkali solution has been tested for adsorption the dye (MB) in aqueous solutions by batch and fixed-bed column.

\section{Materials and methods}

\subsection{Materials and chemicals}

- Methylene Blue dye (MB) with the molecular formula $\mathrm{C}_{16} \mathrm{H}_{18} \mathrm{ClN}_{3} \mathrm{~S}$ and molecular weight 319,852 $\mathrm{g} / \mathrm{mol}$, purchased from Sigma Aldrich. 
- Alkaline solution: sodium silicate powder (Honeywell Riedel-de Haën®, Germany; 18 wt.\% $\mathrm{Na}_{2} \mathrm{O}, 63$ wt. $\% \mathrm{SiO}_{2}, 18$ wt.\% loss on ignition) and sodium hydroxide (ACS AR Analytical Reagent Grade Pellets).

- Fly ash was obtained from Jorf Lasfar power plant in EL Jaddida, Morocco. The chemical composition (wt.\%) of fly ash measured by X-ray Fluorescence (XRF) was: $\left(\mathrm{SiO}_{2}(52.5 \%), \mathrm{Al}_{2} \mathrm{O}_{3}\right.$ (30.2), $\mathrm{CaO}$ (6.27\%), $\mathrm{MgO}(1.23 \%), \quad \mathrm{Fe}_{2} \mathrm{O}_{3} \quad(2.94 \%), \quad \mathrm{SO}_{3}$ $(0.787 \%)$, and LOI ("loss on ignition" $7.12 \%)$ ) The total mass $\left(\mathrm{SiO}_{2}+\mathrm{Al}_{2} \mathrm{O}_{3}=82.7 \%\right)$ indicated the Jorf Lasfar fly ash was Class F.

X-ray diffraction (XRD) analysis was carried out using (Xpert Pro model) diffractometer equipped with a source operating Cu-K $\alpha(1.54060 \AA)$.

Nitrogen adsorption/desorption isotherms were recorded for powdered samples using a Micrometrics model 3Flex 3500 analyzer.

Surface areas were obtained by the Brunauer-EmmettTeller (BET) equation, pore volume and pore size distributions were calculated from the desorption data using the Barrett-Joyner-Halenda (BJH) method. Malvern Zetasizer (nano series) was used to measure the zeta potential of geopolymer matrices well dispersed in deionized water ( $5 \%$ weight suspension). Before each set of measurements, the instrument was calibrated using potassium tungstosilicate solution, and all calculations were performed using the Zetasizer software. The method used is the Dynamic Light Scattering (DLS).

${ }^{29} \mathrm{Si}$ MAS -NMR of samples materials was carried out by MAS NMR Silicon (Magic Angle Spinning). ${ }^{29} \mathrm{Si}$ MAS-NMR spectroscopic characterization was conducted with a Bruker apparatus, model Avance III $600 \mathrm{MHz}$.

\subsection{Batch and fixed-bed column adsorption experiments}

Batch experiments were used to determine the effect of contact time on the MB adsorption capacity. After each batch experiment, the adsorbent was separated by centrifugation. The initial concentration and the concentration of $\mathrm{MB}$ in the solution at the time $(\mathrm{t})$ were determined by UV/VIS spectrophotometer (JASCO V$630 \mathrm{UV} / \mathrm{VIS})$. The amount of adsorption at time $(\mathrm{t}), \mathrm{q}_{\mathrm{t}}$ $(\mathrm{mg} / \mathrm{g})$ was calculated using the equation:

$$
q_{t}=\frac{\left(C_{i}-C_{t}\right)}{m} V
$$

Where $C_{i}$ is the initial concentration $\left(\mathrm{mg} \cdot \mathrm{L}^{-1}\right)$ and $\mathrm{C}_{\mathrm{t}}$, the concentration $\left(\mathrm{mg} . \mathrm{L}^{-1}\right)$ at the time $\mathrm{t}$. $\mathrm{V}$ is the volume of solution (L) and $\mathrm{m}$ is the mass of the adsorbent $(\mathrm{g})$.

Fixed bed column experiments were carried out using a glass column (diam, $1.2 \mathrm{~cm}$; length, $30 \mathrm{~cm}$ ) for adsorption of $\mathrm{MB}$ onto geopolymer at various bed height $(\mathrm{Z}=1 \mathrm{~cm}(2.28 \mathrm{~g}) ; 3 \mathrm{~cm}(5.82 \mathrm{~g}) ; 5 \mathrm{~cm}(8.04 \mathrm{~g}))$ by fixing influent concentration (40 mg/L) and flow rate of 6 $\mathrm{ml} / \mathrm{min}$.

\section{Results and Discussion}

\subsection{Synthesis of the geopolymer and characterization of samples}

\subsubsection{Geopolymer Synthesis}

The alkali activator solution is prepared by mixing sodium hydroxide $(12 \mathrm{M})$ and sodium silicate powder in a weight ratio of 2.5 for $24 \mathrm{~h}$. The geopolymer was elaborated by mixing fly ash with alkaline activator solution in a solid to liquid ratio of 2.5 for $15 \mathrm{~min}$. After mixing, the sample paste was cast in a cylindrical plastic mould for curing at the temperature of $60^{\circ} \mathrm{C}$ for $24 \mathrm{~h}$. After the curing period, the geopolymer obtained was dried in at the ambient temperature for 3 days and crushed to particle size of $(100-200 \mu \mathrm{m}$ for powdered geopolymer and 0.98-1.85 $\mathrm{mm}$ for granulated geopolymer). The obtained samples are stored in a desiccator before their use.

\subsubsection{Characterizations of samples}

$X$-ray diffraction (XRD) analysis

The XRD pattern of fly ash and the geopolymer shown in Fig. 1 illustrates the crystalline phases present in the fly ash and geopolymer namely, quartz and mullite. After geopolymerization process, the shift of peak towards lower angles is due to the formation of new product and the large band between $20^{\circ}$ and $28^{\circ}$ ( 2 Theta) indicates the presence of amorphous aluminosilicate.

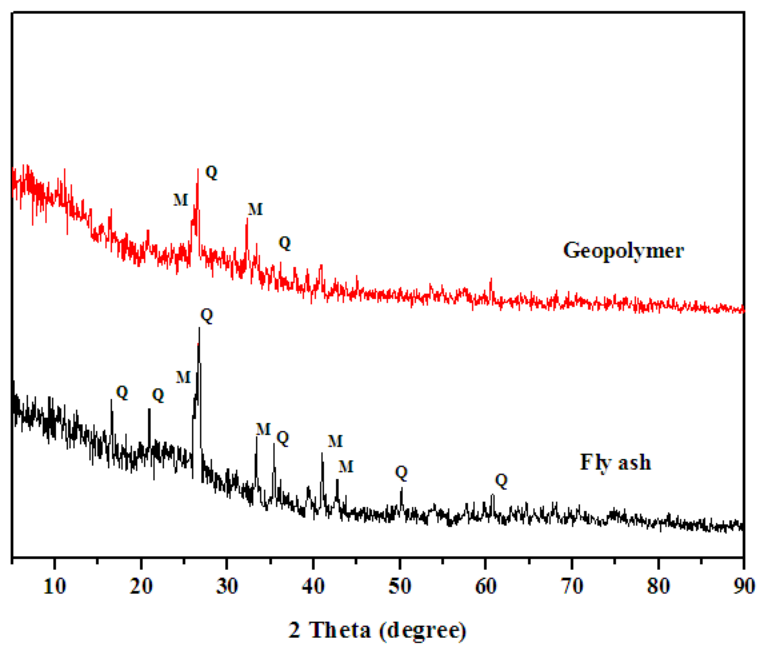

Fig.1. XRD patterns of fly ash and geopolymer (Q-quartz, Mmullite).

The surface area, pore structure properties and zeta potential of geopolymer 
The surface area and porous structure of geopolymer are summarized in Table 1. The BET surface areas, pore volumes and pore sizes of the sample are $2.5080 \mathrm{~m}^{2} / \mathrm{g}$, $0.001567 \mathrm{~m}^{3} / \mathrm{g}$ and $1.1738 \mathrm{~nm}$, respectively. The geopolymer was classified as microporous materials with average pore size up to $2 \mathrm{~nm}$.

Table 1. Textural properties by $\mathrm{N}_{2}$ adsorption/ desorption studies

\begin{tabular}{cc}
\hline Typical parameters & FA- based geopolymer \\
\hline $\mathrm{S}_{\mathrm{BET}}\left(\mathrm{m}^{2} / \mathrm{g}\right)$ & 2.5080 \\
$\mathrm{~S}_{\text {ext }}\left(\mathrm{m}^{2} / \mathrm{g}\right)$ & 2.1338 \\
$\mathrm{~S}_{\text {mic }}\left(\mathrm{m}^{2} / \mathrm{g}\right)$ & 0.3743 \\
$\mathrm{~V}_{\mathrm{t}}\left(\mathrm{m}^{3} / \mathrm{g}\right)$ & 0.001567 \\
$\mathrm{~V}_{\text {mic }}\left(\mathrm{m}^{3} / \mathrm{g}\right)$ & 0.001037 \\
$\mathrm{D}_{\mathrm{p}}(\mathrm{nm})$ & 1.1738 \\
\hline
\end{tabular}

$\mathbf{S}_{\text {BET }}$ : The specific surface area; $\mathbf{S}_{\text {ext }}$ : The external area; $\mathbf{S}_{\text {mic }}$ : The micropore specific surface; $\mathbf{V}_{\mathbf{t}}$ : The total pore volume; $\mathbf{V}_{\text {mic }}$ : The micropore volume; $\mathbf{D}_{\mathbf{p}}$ : The average pore size

Fig.2 shows the zeta potential obtained for the geopolymer. As can be observed in Fig.2, the negative value $(-41.6 \mathrm{mV})$ was observed in the surface zeta potential of geopolymer. This behaviour indicates that the surface of geopolymer is negatively charged and the compound is a condition for the adsorption of the cationic dye existing in aqueous solution.

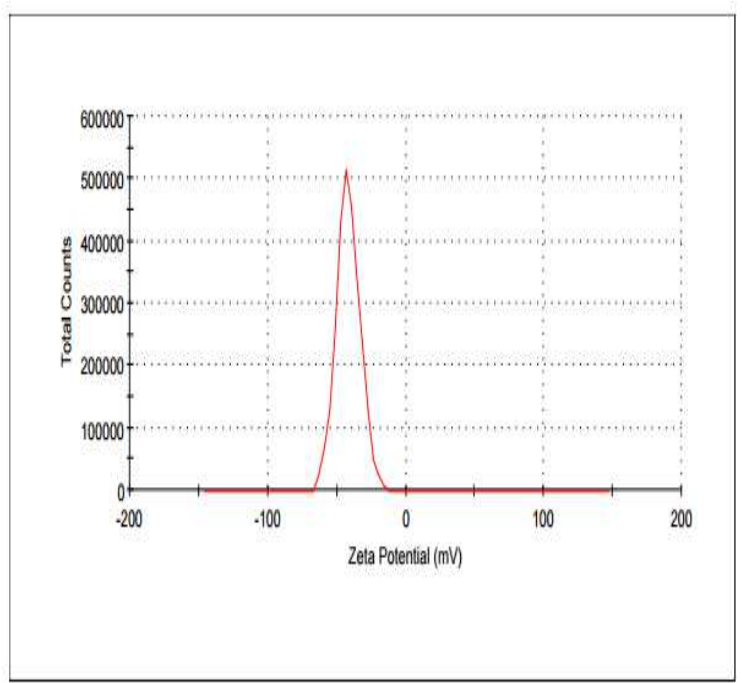

Fig.2. Zeta potential of geopolymer in water

\section{${ }^{29}$ Si RMN MAS analysis}

${ }^{29} \mathrm{Si}$ RMN MAS spectrum of fly ash and geopolymer are shown in Fig.3. ${ }^{29} \mathrm{Si}$ RMN MAS spectrum of fly ash has strong peak at $-107 \mathrm{ppm}$, which demonstrate tetrahedral $\left[\mathrm{SiO}_{4}\right]^{4-}$ coordination $\mathrm{SiQ}_{4}[20-22]$. According to the ${ }^{29} \mathrm{Si}$ RMN MAS spectra of geopolymer, the peak at $-94,66$ ppm indicates the presence of $\mathrm{SiQ}_{4}(2-3 \mathrm{Al})$ in the geopolymer [23]. This result indicates that the chemical structure of fly ash is completely different from the geopolymer one.

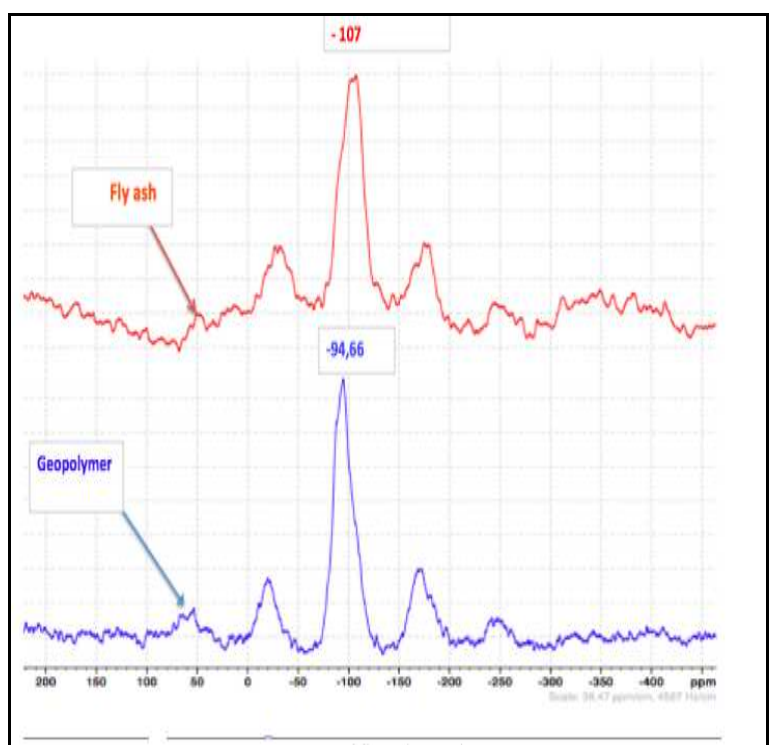

Fig.3. ${ }^{29}$ Si MAS-RMN spectra of fly ash and geopolymer.

\section{Scanning electron microscope (SEM) analysis}

Scanning electron microscopy (SEM) was used to observe the surface texture of fly ash and geopolymer. The SEM image of fly ash (fig 4.a) shows that the sample particles have spherical forms and different sizes. The changes in the morphology of fly ash and geopolymer are illustrated in Fig.4. The results indicate the formation of the new material after activation the fly ash by alkali solution and SEM images shows the porous structure of geopolymer.

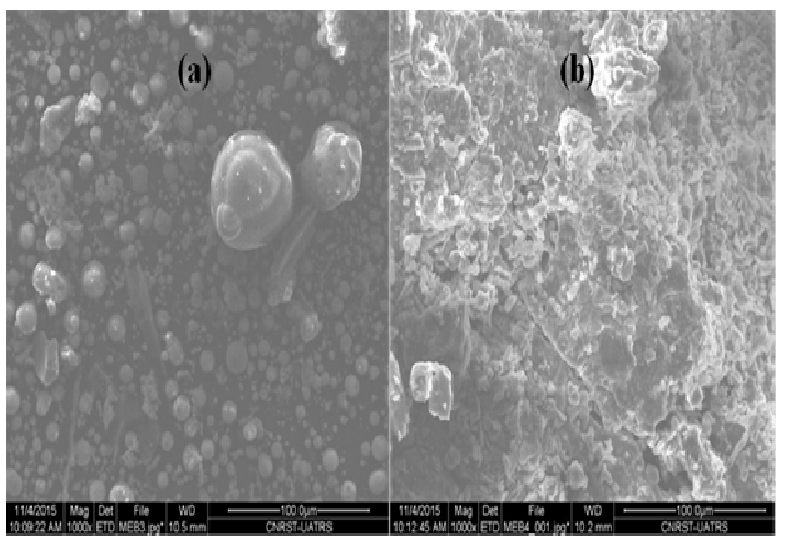

Fig.4. SEM images of the surface the fly ash (a) and geopolymer (b)

\subsection{Adsorption studies}

Effect of the contact time

The effect of the contact time on MB removal was considered by changing the contact time from $30 \mathrm{~min}$ to $210 \mathrm{~min}$. The MB initial concentration was fixed at 40 $\mathrm{mg} / \mathrm{L}$ with a fixed geopolymer dosage $(1 \mathrm{~g} / \mathrm{L})$ and $\mathrm{pH}$ of solution was fixed at 6 . The effect of contact time of MB onto geopolymer is displayed in Fig.5. The results indicated that $\mathrm{MB}$ capacity adsorption occurred in the 
first $120 \mathrm{~min}$ and the adsorption equilibrium was reached at $150 \mathrm{~min}$.

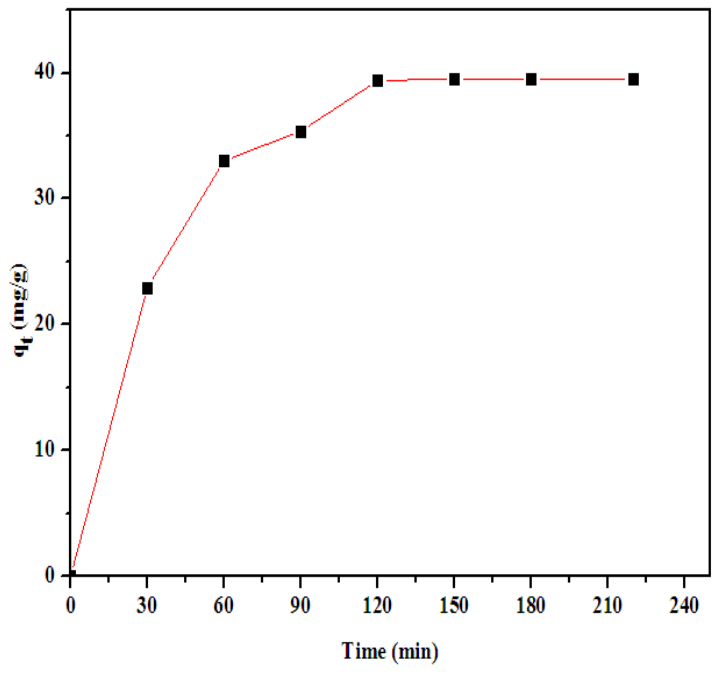

Fig.5. Effect of contact time on adsorption of MB onto geopolymer

\section{Adsorption kinetics}

Several models have been established to describe the adsorption kinetics and the rate-limiting step of the process. They include models of pseudo-first, secondorder kinetic model, model intra-particle diffusion and sorption model Weber and Morris, the relationship of Adam-Bohart Thomas, etc [24]. The adsorption kinetics data of MB using the geopolymer were analyzed with pseudo-first-order [25], pseudo-second-order [26] and intraparticle diffusion kinetic models [27].

The experimental data of MB adsorption on geopolymer were simulated with three models and the results were presented in Table 2 . The correlation coefficients $\left(\mathrm{R}_{1}{ }^{2}\right)$ for pseudo-first-order kinetic model are between 0.718 and 0.926, the correlation coefficients $\left(\mathrm{R}_{2}{ }^{2}\right)$, for the pseudo-second-order kinetic model are between 0.99 and 1 , and the correlation coefficients $\left(\mathrm{R}_{3}{ }^{2}\right)$ for intraparticle diffusion model are between 0.513 and 0.993. On the basis of $\mathrm{R}^{2}$ value, the pseudo second order rate model fit best with experimental data. On other hand, the $\mathrm{q}_{\mathrm{e}}(43.47$ $\mathrm{mg} / \mathrm{g}$ ) calculated value from the pseudo-second-model is close with the experimental value $(39.55 \mathrm{mg} / \mathrm{g})$. This confirmed that the adsorption processes are better represented by pseudo-second-model and the adsorption process is controlled by the chemisorption process. These results indicated that the adsorption occurred probably by surface complexation reaction between cationic dye and negative charged sites on the geopolymer. Similar kinetic results were reported for the adsorption of MB onto spent tea leaves [28], oil palm (Elaeis guineesis) [29] and coalbearing kaolinite [30].

Table 2. Simulated parameters by Pseudo-first-order, Pseudo-second-order and intraparticle diffusion kinetic for adsorption of MB onto geopolymer

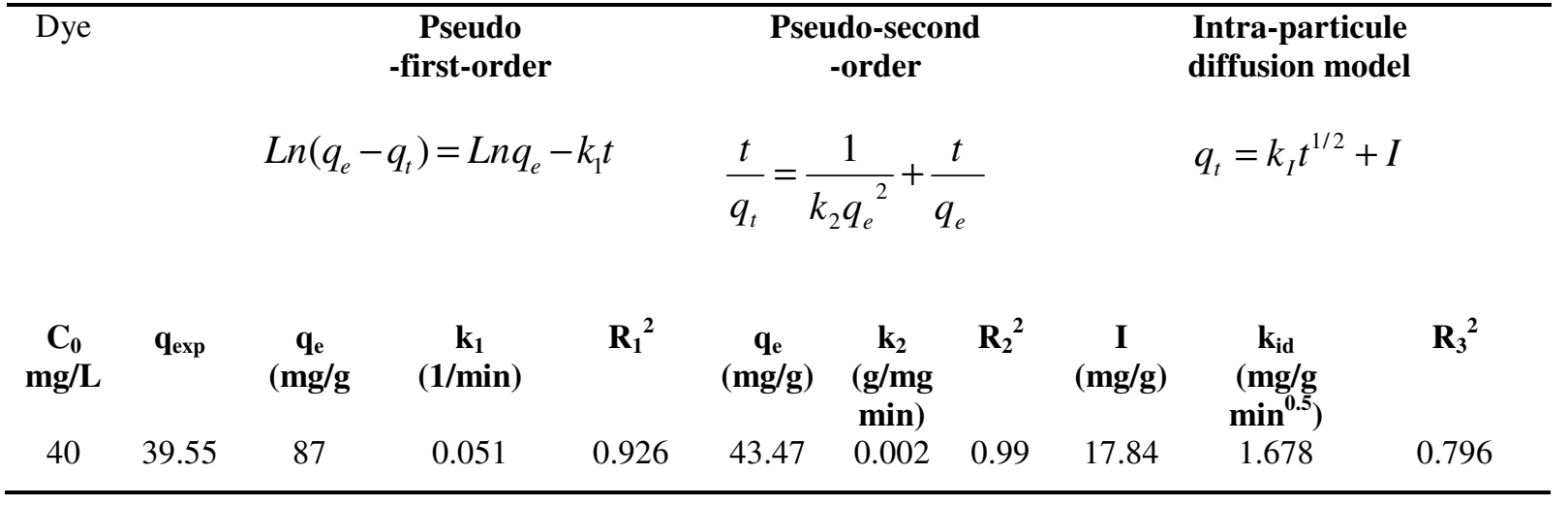

Where:

$\mathbf{q}_{\mathbf{e}}$ : The mass of adsorbate per unit mass of adsorbent at equilibrium; $\mathbf{q}_{\mathbf{t}}$ : the mass of adsorbate per unit mass of adsorbent at time; $\mathbf{k}_{\mathbf{1}}$ : Pseudo-first order rate constant $\left(\mathrm{min}^{-1}\right)$. $\mathbf{k}_{\mathbf{2}}$ : pseudo-second order rate constant $(\mathrm{g} /(\mathrm{mg} . \mathrm{min}))$, and $\mathbf{I}$ : The intraparticle diffusion constants $(\mathrm{mg} / \mathrm{g})$.

\subsection{Colum adsorption studies}

Influence of contact time was studied at different bed height and the concentration of $\mathrm{MB}$ was fixed at 40 $\mathrm{mg} / \mathrm{L}$. The breakthrough curves have been determined at various bed heights at $25^{\circ} \mathrm{C}$. The results are illustrated in Fig.6. It can be seen that the breakthrough time and exhaustion times increased with increasing bed height.
This can be explained with the interaction between of cationic dye (positively charge) and geopolymer (negatively charge of surface) is also greater. Similar kinetics behaviour for the adsorption of MB onto various sorbent materials was also reported in the literature [3133]. Various mathematical equations were used to describe column adsorption process. The adsorption kinetics data of MB using geopolymer were analyzed with Thomas [34], Adams-Bohart [35] and Yoon-Nelson 
equations [36]. These models tested for MB adsorption in the column study were summarized in Table 3. For Thomas parameter model, rate constant $\mathrm{k}_{\mathrm{Th}}$ decreased simultaneously with increasing bed height. However, the adsorption capacity increases with the increase in geopolymer mass in height. From these results, it is found that the adsorption capacity usually increases with the increase of adsorbent ratio. For the Yoon-Nelson model, the rate constant $\mathrm{k}_{\mathrm{YN}}$ decreased and the time required for $50 \%$ breakthrough increased with increasing bed height. This phenomenon can be explained by the number of active sites increases with the increases in adsorbent doses in height bed. Similar results were reported by other researchers [37-40]. For the values of AdamsBohart model, the kinetic constant $\mathrm{k}_{\mathrm{AB}}$ decreases simultaneously and the concentration at saturation $\left(\mathrm{N}_{0}\right)$ of column decreases with increasing bed height. This result can be explained by that the decrease the mass transfer resistance between the adsorbate (MB) and adsorbent surface (geopolymer). The kinetic models are found to describe well the breakthrough curves of methylene blue removal. The overall study results showed that the granulated geopolymer have high capacity and potential for removal the organic pollutants from aqueous solutions.

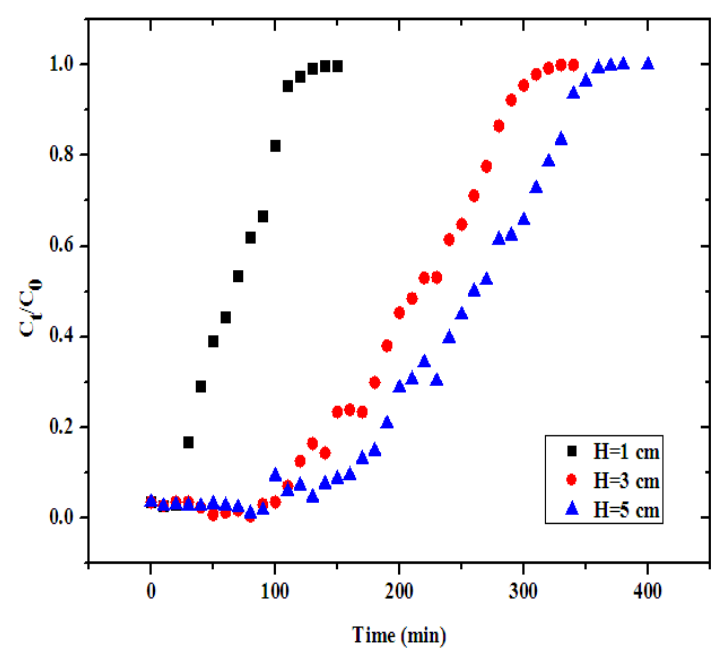

Fig.6. Break through curve of bed height (Initial concentration= $40 \mathrm{mg} / \mathrm{L}$, flow rate $6 \mathrm{~mL} / \mathrm{min}$ )

Table 3. Kinetic parameters for adsorption of MB onto geopolymer in the column study

\begin{tabular}{|c|c|c|c|c|c|c|c|c|c|}
\hline \multirow{5}{*}{$\begin{array}{l}\text { Bed } \\
\text { height } \\
1 \mathrm{~cm} \\
3 \mathrm{~cm}\end{array}$} & \multicolumn{3}{|c|}{ Thomas model } & \multicolumn{3}{|c|}{ Adams-Bohart } & \multicolumn{3}{|c|}{ Yoon-Nelson } \\
\hline & \multicolumn{3}{|c|}{$\operatorname{Ln}\left(\frac{C_{0}}{C}-1\right)=k_{t h} q_{0} \frac{m}{F}-k_{t h} C_{0} t$} & \multicolumn{3}{|c|}{$\operatorname{Ln} \frac{C}{C_{0}}=k_{A B} C_{0} t-k_{A B} N_{0} \frac{H}{v}$} & \multicolumn{3}{|c|}{$\operatorname{Ln} \frac{C}{C_{0}-C}=k_{Y N} t-k_{Y N} t_{50}$} \\
\hline & $\underset{(\mathbf{m g} / \mathbf{g})}{\mathbf{q}_{0}}$ & $\mathbf{k}_{\mathrm{TH}}$ & $\mathbf{R}^{2}$ & $\mathbf{k}_{\mathrm{AB}}$ & $\mathbf{N}_{0}$ & $\mathbf{R}^{2}$ & $\mathbf{K}_{\mathbf{Y N}}$ & $\mathbf{t}_{\mathbf{5 0}}$ & $\mathbf{R}^{2}$ \\
\hline & $6.475^{\circ}$ & $2.075 .10^{-3}$ & 0.857 & $6.10^{-4}$ & 5240 & 0.782 & 0.083 & 59.20 & 0.857 \\
\hline & 7.820 & $7.5 .10^{-4}$ & 0.816 & $3.5 .10^{-5}$ & 4070 & 0.828 & 0.03 & 189.56 & 0.816 \\
\hline $5 \mathrm{~cm}$ & 6.496 & $6.5 \cdot 10^{-4}$ & 0.764 & $2.75 .10^{-5}$ & 2875 & 0.915 & 0.026 & 217.04 & 0.764 \\
\hline
\end{tabular}

Where:

Thomas model: $\mathbf{C}_{\mathbf{0}}$ : The initial concentration $(\mathrm{mg} / \mathrm{L}), \mathbf{C}$ : effluent concentration at the time $\mathrm{t}(\mathrm{mg} / \mathrm{L})$, m: Mass of the adsorbent (g), F: flow rate $(\mathrm{mL} / \mathrm{min}), \mathbf{k}_{\mathbf{t h}}$ : Thomas model rate constant $(\mathrm{mL} / \mathrm{min} \mathrm{g}), \mathbf{q}_{\mathbf{0}}$ : The column adsorption capacity (mg/g).

Adams-Bohart model: $\mathbf{C}_{\mathbf{0}}$ : The initial concentration $(\mathrm{mg} / \mathrm{L}), \mathbf{C}$ : effluent concentration at the time $\mathrm{t}(\mathrm{mg} / \mathrm{L}) . \mathbf{k}_{\mathbf{Y N}}$ : the Yoon-Nelson rate constant $\left(\mathrm{min}^{-1}\right), \mathbf{H}$ : height of adsorbent in fixed bed in the column $(\mathrm{cm}), \mathbf{N}_{\mathbf{0}}$ : the volumetric sorption capacity $(\mathrm{mg} / \mathrm{L}), \mathbf{v}$ : The velocity $(\mathrm{cm} / \mathrm{min})$.

Yoon-Nelson model: $\mathbf{C}_{\mathbf{0}}$ : The initial concentration $(\mathrm{mg} / \mathrm{L}), \mathbf{C}$ : effluent concentration at the time $\mathrm{t}(\mathrm{mg} / \mathrm{L})$. $\mathbf{k}_{\mathbf{Y N}}$ : is the rate constant. $\mathbf{t}_{\mathbf{5 0}}$ : The time required for $50 \%$ Adsorbate breakthrough (min).

\section{Conclusions}

This study thoroughly reviewed the application of geopolymer for the treatment of dye-containing aqueous solution. A physico-chimical characterization of the samples indicates the formulation of geopolymer by fly ash and alkaline activator solution, and suggests that the adsorbent have functional groups suitable to remove MB. The kinetic studies for batch experiment reveal that $\mathrm{MB}$ adsorption on geopolymer was rapid and equilibrium was reached within $120 \mathrm{~min}$. The kinetics of MB adsorption onto adsorbent was followed pseudo-second-order kinetic model. The breakthrough curves of column both showed that the geopolymer favors the adsorption of MB. The results of this research indicated that the geopolymer synthesized by fly ash and alkaline activator could be used adequately for the treatment of aqueous solution contaminated with cationic dye. 


\section{References}

1. S. Nawar, H. Doma, Sci. Total Environ. 79, 271-279 (1989)

2. M. A. M. Salleh, D. K. Mahmoud, W. A. Karim, A. Idris, Desalination. 280, 1-13 (2011)

3. C. Tocchi, E. Federici, L. Fidati, E. Manzi, V. Vincigurerra, M. Petruccioli, Water Res. 46, 33343344 (2012)

4. Y. Zhang, C. Causserand, P. Aimar, J.P. Cravedi, Water Res. 40, 3793-3799 (2006)

5. S. Stopic, B. Friedrich, A. Widigdo, Metalurgia. 13, 27-34 (2007)

6. D.J. Ennigrou, L. Gzara, M.R. Ben Romdhane, M. Dhahbi, Desalination. 246, 363-369 (2009)

7. A. Sandoval, C. Hernández-Ventura, T. E. Klimova, Fuel. 198, 22-30 (2017)

8. Y. Al-Ani, Y. Li, J. Taiwan Ins. Chem. Eng. 43, 942947 (2012)

9. Y. Y. Sia, I.A.W. Tan, M.O. Abdullah, MATEC Web Confer. 87, 03010 (2017)

10. N. Barka, A. Assabane, A. Nounah, L. Laanab, Desalination. 235, 264-275 (2009)

11. L. Li, S. Wang, Z. Zhu, J. Colloid Interface Sci. 300, 52-59 (2006)

12. K. Bhattacharyya, S. Sengupta, G. K. Sarma, Appl. Clay Sci. 99, 7-17 (2014)

13. D. Pathania, S. Sharma, P. Sing, Arab. J. Chem. 10, S1445-S1451 (2017)

14. Y. Zhang, L. Liu, Particuology. 11, 353-358 (2013)

15. T.W. Chenga, M.L. Leea, M.S. Koa, T.H. Uenga, S.F. Yang, Appl. Clay Sci. 56, 90-96 (2012)

16. L. Li, S. Wang, Z. Zhu, J. Colloid Interface Sci. 300, 52-59 (2006)

17. A. Jusoh, Y. K. Tam, A.G. Liew, M. J. Megat, K. Saed, Int. J. Eng. Tech. 1, 58-63 (2004)

18. T.W. Cheng, M.L. Lee, M.S. Ko, T.H. Ueng, S.F. Yang, Appl. Clay Sci. 56, 90-96 (2012)

19. C. Smaranda, M.C. Popescu, D. Bulgariu, T. Malutan, M. Gavrilescu, Process Saf. Environ. Prot. Process (2016), http://dx.doi.org/10.1016/j.psep.2016.06.027

20. F. Škvára, L. Kopecký, J. Němeček, Z. Bittnar, Ceramics-Silikáty. 50, 208-215 (2006)

21. N.P. Bansal, J.P. Singh, W.M. Kriven, H. Schneider, Ceram. Trans. 153, 175-186 (2003)

22. J.G.S. van Jaarsveld, J.S.J. van Deventer, L. Lorenzen, Miner. Eng. 10, 659-669 (1997)

23. P.S. Singh, T. Bastow, T. Trigg, J. Mater. Sci. 40, 3951-3961 (2005)

24. J. Febrianto, A.N. Kosasih, J. Sunarso, Y. Ju, N. Indraswati, S. Ismadji, J. Hazard. Mater. 162, 616-645 (2009)

25. S.S. Gupta, K.G. Bhattacharyya, Adv. Colloid Interface Sci. 162, 39-58 (2011)

26. Y.S. Ho, G. McKay, Process Biochem. 34, 451-465 (1999)

27. T. Furusawa, J.M. Smith, Aiche J. 20, 88-93 (1974)

28. B.H. Hameed, J. Hazard. Mater. 16, 753-759 (2009)

29. H.D. Setiabudi, R. Jusoh, S. Suhaimi, S.F. J. Masrur, Taiwan. Inst. Chem. Eng. 63, 363-370 (2016)

30. W. Goa, S. Zhao, H. Wu, W. Deligeer, S. Asuha. Appl. Clay Sci. 126, 98-106 (2016)
31. R. Han, Y. Wang, X. Zhao, Y. Wang, F. Xie, J. Cheng, M. Tang, Desalination. 245, 284-297 (2009)

32. O. Hamdaoui, J. Hazard. Materi. B138, 293-303 (2006)

33. Y. Zhuang, F. Yu, J. Chen, J. Ma, J. Environ. Chem. Eng. 4, 147-156 (2016)

34.Z. Aksu, F. Gönen, Process Biochem. 39, 599-613 (2004)

35. M. Calero, F. Hernáinz, G. Blázquez, G. Tenorio, M.A. Martín- Lara, J. Hazard. Mater. 171, 886-893 (2009)

36. Z. Aksu, S.S. Cagatay, F. Gonen, J. Hazard. Mater. 143, 362-371 (2007)

37. M. Ratnamala, M. Rahul, S. Sameer, M. Vaani, Omkar, T. Devdatt, Asian. J. Chem. 29, 191-195 (2017)

38. N. Kannan, S. Murugavel, Elctron. J. Environ. Agric. Food Chem. 6, 1860-1868 (2007)

39. P. Sivakumar, P.N. Palanisamy, International Journal of Chem. Tech. Research. 1, 502-510 (2009)

40.Z. Zulfadhly, M.D. Mashitah, S. Bhatia, Envion. Pollut. 112, 463-470 (2001) 